\title{
Capacity Constraints, Profit Margins and Stock Returns
}

November 9, 2009

\begin{abstract}
This paper studies the effects of capacity utilization on accounting profit margins and stock returns. Since accounting profit margins represent the average profit per unit and not the economists' concept of unit contribution margin, the marginal/variable profit per unit, a firm with idle capacity can increase its profit margins by increasing sales (output). However, if the firm is operating at full capacity, an increase in output must be preceded by an increase in capacity (and fixed costs) resulting in lower profit margins. Our empirical findings suggest that firms' profit margins increase in sales when there is idle capacity, but decreases in sales when the firm approaches full capacity. We show that firms experiencing high growth in sales, operating in industries with high capacity utilization, experience abnormally low stock returns in the following period.
\end{abstract}

JEL classification: E32, G12, G14, M41.

Keywords: accounting valuation, abnormal returns, capacity utilization, profitability, profit margins 


\section{Introduction}

Earnings is the most common measure in finance and accounting for firm-level cash flow news (see e.g., Vuolteenaho, 2002). These earnings, which are reported in the firm's financial statements, are prepared subject to accounting principles. One of these principles, the socalled matching principle, dictates that an expense is recorded when an asset is consumed to generate revenues. For example, the fixed acquisition cost of a production facility is initially capitalized (recorded as an asset on the balance sheet) and is later depreciated (in the income statement) as an expense over the estimated useful economic life of the production facility. Similarly, fixed production costs are included in the cost of inventory and are expensed in the income statement when the inventory is sold and the revenues are recognized. This principle suggests that accounting expenses include both fixed and variable costs and therefore the expenses represent total cost, and not simply variable or marginal cost. Consequently, accounting profit margins represent average profit per unit and not contribution margin or marginal/variable profit per unit.

The implications of capacity utilization have not escaped the Financial Accounting Standards Board (FASB). Taking the implications of capacity utilization into account, the FASB recently issued the Statement of Financial Accounting Standards (SFAS) No. 151 dealing with inventory costs and idle capacity: "The accounting for inventory costs, in particular, abnormal amounts of idle facility expense, freight handling costs and spoilage... be recognized as current-period charges." It also specifies that, "Although the amount of fixed cost allocated to each unit of production is based on the normal capacity, the unallocated overheads and abnormal costs due to abnormal idle capacity are recognized as an expense in the period they are occurred."

In sum, under Generally Accepted Accounting Principles, all accounting-based profit margins invariably reflect returns to scale. In this vein, Roychowdhury (2006) and Gunny (2009) provide evidence suggesting that firms opportunistically overproduce to increase short-run profits and meet earnings benchmarks. ${ }^{1}$ In our paper, we focus on demand driven production

\footnotetext{
${ }^{1}$ Capacity utilization may also be the reason why sales growth is more persistent than earnings growth
} 
(as refelcted by sales growth). If a manufacturer can produce additional quantities without adding to the cost of the plant (i.e., the plant has idle capacity), the average cost per unit will tend to decline from an increase in production. Consequently, accounting profit margins, which reflect total cost, will increase. In other words, growth in sales for a company with idle capacity will result in higher profit margins. However, if the firm is operating at full capacity, an increase in output must be preceded by an increase in capacity, such as plant expansion. Thus, for a company operating near or at full capacity, growth in sales can result in lower profit margins, reflecting the increase in fixed costs. ${ }^{2}$

Although capacity utilization is an important determinant of profit margins (See also Corrado and Mattey, 1997), firms are not required to disclose this information. Therefore, investors are not fully able to anticipate when a firm will be required to make an additional investment to support its projected growth in sales/output. In this paper, we investigate whether capacity constraints indeed predict changes in profit margins and whether investors appear to fully incorporate the implications of capacity constraints in forming expectations and prices. While capacity utilization is likely a major source of variation in profit margins, this issue has not been explored in the financial accounting literature. ${ }^{3}$

We begin by motivating our hypotheses using a simple example of a single firm (a monopoly) facing a linear demand function and costly capacity. With increasing returns to scale, the average cost per unit produced decreases with output. However, the average and why investors react more strongly to sales-growth driven earnings surprises (e.g., Ertimur, Livnat and Martikainen, 2003).

${ }^{2}$ Increasing capacity utilization may increase costs related to set-ups and processing in a stochastic operation environment as suggested by Banker, Datar and Kekre (1998). We do not consider this type of costs in our model. But as long as firms plan their capacities by incorporating the uncertainties, we do not expect this will affect our prediction on the systematic relationship between firms' profit margins and capacity utilization.

${ }^{3}$ Prior studies such as Badia, Melumad and Nissim (2008) and Banker and Chen (2006) typically focus on the earnings implications by decomposing costs into variable versus fixed components, etc. Banker and Hughes (1994) examine a monopoly firm's pricing and capacity decisions involving non-variable support activity costs. But, their focus is on the economic sufficiency of the activity-based cost accounting as a source of information to marketing and production decisions. 
cost per unit may increase when the increase in output requires additional investment in capacity. The increase in fixed costs due to capacity constraints thus results in a non-monotonic relation between the average cost and output.

Our empirical analysis first explores the effect of capacity utilization on profit margins. Since firm-level estimates of capacity utilization are unavailable, we employ industry-level measures of capacity utilization produced by the Federal Reserve. These data is available for Manufacturing, Mining and Utilities, so we focus our empirical analysis on these industries. The sectors covered by this database account for the bulk of variation in the national output of the United States.

We proceed by empirically testing the relation among accounting profit margins, output, and capacity utilization. Our results are consistent with the notion that accounting profit margins reflect the implications of returns to scale. Specifically, we find that profit margins improve following periods of revenue growth. Consistent with this, we show that firms operating in industries with higher capacity utilization have higher profit margins. These findings are also apparent in aggregate-level data, in which aggregate profit margins are positively related to overall US capacity utilization index. We also find that the relation between sales growth and profit margins is non-linear. We find that firms operating in industries with high capacity utilization experience declines in the profit margins. Specifically, we establish that the relation between future profit margins and an interaction term of sales growth and industry-capacity utilization is negative.

After demonstrating that capacity utilization is an important determinant of profit margins, it is of interest to investigate whether such information would be useful to investors. Specifically, we sort our industries into five portfolios based on the interaction of industrylevel capacity utilization and industry-level sales growth. Our findings suggest that industries with high capacity utilization and high sales growth underperform (have lower future returns) compared to industries with low capacity utilization and/or low sales growth. In other words, our findings suggest that absent information regarding capacity utilization, investors are unable to identify the expected decline in profit margins due to additional investments in capacity. In addition to the industry-level analysis, we sort firms into five 
portfolios based on the interaction of industry-level capacity utilization and firm-level sales growth. Our findings suggest that firms operating in industries with high capacity utilization and high (firm-level) sales growth underperform (have lower future returns) compared with firms operating in industries with low capacity utilization and/or have low (firm-level) sales growth.

Since our hypotheses also suggest that capacity constraints will increase capital expenditures and fixed costs, we test whether our results are more pronounced in firms that incur significant increases in capital expenditures. In addition to growth in capital expenditures, we use the ratio of capital-expenditures-to-depreciation to test for increases in capital expenditures aimed at increasing capacity. Consistent with our hypotheses, we find that firms with high sales growth operating in industries with high capacity utilization tend to increase their capital expenditures. In addition, the findings imply that the reversal in profit margins is more pronounced in cases with high growth in capital expenditures.

Finally, our tests imply that our findings are not subsumed by other known anomalies, such as the price momentum and accrual anomaly. Specifically, we include the momentum factor (Jagadeesh and Titman, 1993; and Carhart, 1997) and an accrual factor (Sloan, 1996). We construct our accrual factor using 10 portfolios sorted based on accruals. Our factor is the returns of the low accrual portfolio minus the returns on a high accrual portfolio. Our results imply that the abnormal returns obtained by sorting firms based on the interaction of sales growth and capacity utilization are not subsumed by previously known anomalies, i.e., price momentum and accruals. Finally, we also use Fama-MacBeth (1973) regressions controlling for the book-to-market ratio, size, and accruals. The interaction term of sales growth and capacity utilization loads negatively and statistically significant in the FamaMacBeth regressions as well.

Our finding of negative future stock return for capacity-constrained firms is consistent with the hypothesis that investors cannot fully incorporate the implications of capacity constraints when they lack of firm-specific information about capacity utilization. However, it is possible that this result is not driven by mispricing but by the change in systematic risk. Carlson, Fisher and Giammarino (2006) argue that growth/expansion options are riskier 
than assets in place, therefore new investments transform riskier options into assets in place, reducing the systematic risk and expected returns. Since increasing capacity is also exercising the growth option, our finding is also consistent with their argument that firms' risks are reduced after expansion of capacity and future returns as a result are lower. From this perspective, it is still beneficial to require more disclosure of capacity utilization information or future expansion plans of the firm, as the disclosure will resolve more uncertainty ex-ante and stablize the market.

The rest of the paper proceeds as follows. Section 2 presents a simple model to develop our main hypotheses. Section 3 describes our data. Section 4 reports the empirical results for the implications of capacity constraint on profit margins and stock returns. Section 5 concludes.

\section{A Simple Illustration}

In this section, we demonstrate the implication of capacity constraints on a firm's profit margins and draw our hypotheses. For simplicity, we use a single firm monopoly, but the conclusions can be easily shown using a Cournot model with $n$ identical competitors. ${ }^{4}$

Assume a single firm (a monopoly) facing the following demand function:

$$
P=A-q
$$

where $P, A$ and $q$ denotes price, demand and output, respectively. We assume that the firm has contact marginal cost, $c$. Further, we assume that the firm must incur a fixed capacity cost of $F$ for each $\bar{q}$ units produced per period. Thus, the firm's cost function, $C(q)$, is as follows:

\footnotetext{
${ }^{4}$ The results might vary depending on the nature of competition. Levitan and Shubik (1972) shows in a duopoly model with two firms limited by capacity constraint that either a Cournot quantity strategy equilibrium or a Bertrand price strategy equilibrium may appear when the capacity varies.
} 


$$
C(q)=c \cdot q+F \cdot \text { integer }\left(\frac{q}{\bar{q}}+1\right)
$$

For simplicity, assume that $A>c+F$ to assure that the firm always covers its average cost, i.e., positive profits.

To choose the optimal output the firm maximizes its profits:

$$
\max _{q} P \cdot q-C(q)=(A-q) \cdot q-c \cdot q-F \cdot \operatorname{integer}\left(\frac{q}{\bar{q}}+1\right)
$$

Let, $n=$ integer $\left(\frac{A-c}{\overline{2 q}}\right)$. Solving for the optimal price and output results in the following profit margin:

$$
P M=\left\{\begin{array}{cc}
1-\frac{n \bar{q} c+n F}{(A-n \bar{q}) \cdot n \bar{q}} & \underline{A}<A<\bar{A} \\
1-\frac{c+\frac{2 F}{A-c}(n+1)}{(A+c) / 2} & \text { Otherwise }
\end{array}\right\}
$$

Equation (4) implies the following empirical predictions (see Appendix): 1) For firms with idle capacity, profit margins are increasing in output, 2) Profit margins are increasing in capacity utilization, and 3) For firms approaching full capacity, profit margins are declining in output. In addition, this illustration implies that the profit margins would decline in output as the firms choose to increase their capacity.

The predictions following from Equation (4) and stated above are apparent in the numerical example illustrated in Figure 1. For this numerical example, we assume that $F=90$, $\bar{q}=10, c=5$, and the demand $A$ starts from 50 with a growth rate of $2 \%$. Panel A plots total production costs and capacity utilization. The figure illustrates that full product costs spikes up consistently following periods where the firm approaches its capacity constraint. Panel B plots the firm's profit margin and capacity utilization. Consistent with Panel A, profit margins generally increase with capacity utilization, but declines following periods where firms approach full capacity.

The illustration above suggests a non-linear relation between profit margins and sales growth. Specifically, the illustration suggests the following empirical model and predictions: 


$$
P M_{i, t}=\alpha_{i, t}+\beta_{i} \cdot \Delta \text { Sales }_{i, t-1}+\gamma_{i} \cdot T C U_{i, t-1}+\delta_{i} \cdot \Delta \text { Sales }_{i, t-1} \cdot T C U_{i, t-1}+\varepsilon_{i, t}
$$

where $\Delta$ Sales $_{i, t}$ denotes the growth in sales during period $t$ and $T C U_{i, t}$ denotes capacity utilization. The illustration implies the following empirical predictions: 1) $\left.\beta_{i}>0,2\right) \gamma_{i}>0$ and 3) $\delta_{i}<0$. Note that $T C U_{i, t}=\left[q_{t} / \bar{q}-\operatorname{integer}\left(q_{t} / \bar{q}\right)\right]$. Similar predictions can be made with regards to changes in profit margins, $\triangle P M_{i, t}$.

\section{Data}

Our data on the industry capacity utilization comes from the statistical data by the Federal Reserve Board, ${ }^{5}$ which provides the annual data for 26 industries. Most of them are manufacturing and utility industries. ${ }^{6}$ Table 1 lists the definition and NAICS classification codes for these 26 industries. Our sample period is limited to 1977-2008 because of the availability of the industry level capacity utilization data. We then retrieve the financial information from the COMPUSTAT annual file for firms in the 26 industries defined in Table 1 . We exclude the top and bottom $5 \%$ of firms ranked by the main variables constructed in the tests, i.e, profit margin, capital expenditure growth and sales growth respectively. We also require lagged four years financial data available for each firm. Our final sample consists of 44,958 firm-year observations from 1977 to 2008, with available financial information in the COMPUSTAT annual file. Given that our sample is limited to a small number of industries, we do not require the same fiscal year end for the firms to be included in our sample. The sample size is reduced to 33,113 observations when we perform the time-series portfolio return test which requires the CRSP monthly return data available.

We first plot the time series of quarterly aggregate profit margin and total capacity utilization from 1967 to 2008 in Figure 2. The aggregate profit margin is measured by the ratio

\footnotetext{
${ }^{5}$ http://www.federalreserve.gov/releases/G17/g17caputl.txt

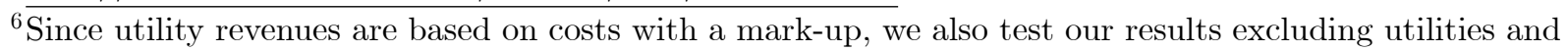
the results remain unchanged.
} 
of aggregate pre-tax income over aggregate sales for all firms in the COMPUSTAT North American sample. The quarterly total capacity utilization is retrieved from the Federal Reserve Board System, and is the total index of capacity utilization in the whole economy. Figure 2 shows that the aggregate profit margin tends to move together with the total capacity utilization, although profit margin exhibits higher volatility than the capacity utilization over the time period. The trend in Figure 2 is consistent with the simulation result in Figure 1b following our model's prediction.

The key variables at the firm year level in the empirical tests are constructed as follows. $T C U_{t}$ is the average total capacity utilization in year $t$ for the industry each firm belongs to. $P M_{i, t}$ is the profit margin in year $t$ for firm $i$, defined as PretaxIncome $e_{i, t} /$ Sales $_{i, t}$. CAPG $_{i, t}$ is the growth in capital expenditure in year $t$ for each firm $i$. For the sales growth measure, we use several proxies based on the sales growth in the different time horizons: $S A L E G 1_{t}$, $S A L E G 2_{t}, S A L E G 3_{t}$, and $S A L E G 4_{t}$. Each $S A L E G j_{t}$ is defined as the compounded sales growth rate in the last $j$ years, i.e.,

$$
S A L E G j_{t}=\frac{S A L E S_{t-1}}{S A L E S_{t-2}} \cdot \frac{S A L E S_{t-2}}{S A L E S_{t-3}} \cdots \frac{S A L E S_{t-j}}{S A L E S_{t-j-1}}=\frac{S A L E S_{t-1}}{S A L E S_{t-j-1}}
$$

where $S A L E S_{i, t}$ is the sales in year $t$ for each firm $i$.

Table 2 provides descriptive statistics for these key variables. Average total capacity utilization for our sample industries is $80.19 \%$, with a minimum of $37.41 \%$ and maximum of 97.84\%. We find that both these two extreme observations are in the industry of 'Support activities for mining', which might reflect some major structuring change in the industry capacity. We also run our test without including observations in this specific industry, and our results still hold. The mean and median of average profit margin for our sample firms are $5.8 \%$ and $6.8 \%$ respectively, with a standard deviation of $11.8 \%$. The profit margin distribution is a little skewed to the left. The average lagged one year sales growth rate is about $8.7 \%$, while the compounded two (three, and four) years sales growth is $20.7 \%(34.7 \%$ and $52.2 \%$ ). Capital expenditure grows at $18.3 \%$ on average, with a standard deviation of $60.3 \%$.

Table 2 also provides evidence supporting our hypothesis that sales growth results in 
higher capacity utilization. Panels $\mathrm{B}$ and $\mathrm{C}$ report industry-level and firm-level pairwise correlations between sales growth and capacity utilization. The correlation between industrylevel sales growth and industry-level capacity utilization varies from 0.275 to 0.342 . The correlation between firm-level sales growth and industry-level capacity utilization varies from 0.054 to 0.103 . These correlations suggest that firms/industries with high sales growth do experience increases in capacity utilization and will eventually require additional investment to increases sales.

\section{Empirical results}

\subsection{Capacity Constraint and Profit Margins}

Our first empirical test examines the effect of sales growth and capacity utilization on profit margins. We perform a pooled regression as described in Equation (5) using 44,958 firm-year observations, controlling for the last period profit margin and last period capital expenditure growth. Table 3 reports the regression results using different measures of sales growth as defined in the data section. The interaction between $S A L E G j_{t}$ and $T C U_{t-1}$ is the measure of capacity constraint which captures the non-linearity in the relationship between sales growth and profit margin. Our tests are estimated with robust standard error including year fixed effect and clustered by firm.

As shown in Table 3, capacity utilization in the last period is positively related to the profit margin in the current period as the coefficients of $T C U_{t-1}$ are all positive and statistically significant in all regressions. The coefficients vary from 0.087 to 0.144 and the $t$-statistics is most significant using the compounded two years sales growth measure at 4.09. Sales growth in the last period is also positively related to the current profit margin in all regressions, but only the first two measures show statistically significant results with the $t$-statistics of 1.81 and 2.45 respectively. The coefficients of the interaction term, $S A L E G j_{t} * T C U_{t-1}$, in all regressions are shown to be negative varying from -0.024 to -0.087 and are statistically significant in most cases except the four years compounded growth 
measure. These results are consistent with our predictions that, in general, when the firm increases its capacity utilization the profit margin will increase; and when the output grows the profit margin will also increase if it has not approached the capacity constraint, indicating an increasing return to scale. However, when the firms with high sales growth in the past are also operating with high capacity utilization, they are more likely to experience decline in the profit margin.

We also control for the capital expenditure growth in this regression. The results show that capital expenditure growth in the last period $\left(C A P X G_{t-1}\right)$ is negatively related to the current profit margin, which is consistent with the explanation that when firms invest in new capital expenditures and increase fixed cost, their profit margins will decline as a result. We are going to explore this point in more detail in the later section.

Our measure using profit margins takes into account that some idle capacity expenses are recognized into current period charges other than production costs (Before SFAS 151, some firms may also follow this practice). But we also perform the test in Table 3 using the measure of gross profit margin (Sales-COGS/Sales). Our results show a similar effect of capacity constraint on the gross profit margin at the firm level, though it is statistically insignificant. However, we obtain statistically significant results when we perform the test of gross profit margin at the industry level, i.e., regress the industry mean (median) gross profit margin on the industry mean (median) of all independent variables including last period gross profit margin, capital expenditure growth, sales growth, and industry total capacity utilization. ${ }^{7}$

Our hypothesis implies that in the long run the effects of capacity utilization will disappear. For example, Figure 1 implies that if one uses the average profit margin over the long-run, the "kink" in profit margins should disappear. In untabulated results, we use a rolling five-year average profit margin instead of the one period ahead profit margin to repeat the test in Table 3. Consistent with the implications of Figure 1, we find no evidence of a negative relation between the interaction of $S A L E G j_{t} * T C U_{t-1}$ and long-run profit margins.

\footnotetext{
${ }^{7}$ For the profit margin regression in Table 3, the results are not statistically significant at the industry level.
} 


\subsection{Capacity Constraint and Stock returns}

Given that the high growth and high capacity utilization firms are more likely to experience a decline in profit margin due to the capacity constraint, the capacity utilization information should be relevant to investors. We then test whether investors can identify the expected decline in the profit margin due to capacity constraints.

Specifically we form portfolios based on the capacity constraint variable $\left(S A L E G j_{t} *\right.$ $\left.T C U_{t-1}\right)$ and test whether abnormal returns are associated with the capacity constraint. To form the portfolio, for each month, stocks are sorted into five groups based on the interaction $S A L E G j_{t} * T C U_{t-1}$ available at the end of the previous month. To ensure only recent information is incorporated, we require the information used to sort the portfolios, i.e., the firm's annual report, be issued within last 3 months. Therefore our portfolio composition changes as firms with new earnings announcements are included in the portfolio over time. The portfolio return is calculated as the equal weighted monthly return. We estimate the monthly excess return using the four factor model with Fama-French three factors (Fama and French, 1993) and the Momentum factor.

Specifically, we use the following asset-pricing model to estimate abnormal returns, $\alpha_{p}$ :

$R_{p, t}-R_{f, t}=\alpha_{p}+\beta_{p, M} \cdot\left(R_{M, t}-R_{f, t}\right)+\beta_{p, S M B} \cdot S M B_{t}+\beta_{p, H M L} \cdot H M L_{t}+\beta_{p, U M D} \cdot U M D_{t}+\varepsilon_{p, t}$

$R_{M, t}$ denotes the returns on the value-weighted market returns, and $R_{f, t}$ is the risk free rate. $R_{p, t}$ is the equal-weighted returns on our portfolios sorted based on the interaction $S A L E G j_{t} * T C U_{t-1}$ available at the end of the previous month. $H M L_{t}, S M B_{t}$, and $U M D_{t}$ are the risk factors sorted based on book-to-market, size and momentum, respectively. The risk factors are extracted from the Fama-French portfolios on the Wharton Research Data Services (WRDS).

Table 4 presents the industry-level portfolio tests results. The table reports the results for the portfolios formed based on the information available within last 3 months. Panels A-D reports results using one-year (Panel A) to four-year (Panel D) sales growth to form portfolios. Using one-year sales growth, i.e., $S A L E G 1_{t} * T C U_{t-1}$, to form portfolios yields 
portfolio returns that decrease from the lowest quintile group to the highest quintile group. The abnormal monthly return $\left(\alpha_{p}\right)$ in Panel $\mathrm{A}$ is $1.1 \%$ on the lowest quintile group and $0.4 \%$ on the highest quintile group, and the difference between them $(0.7 \%$ monthly abnormal returns) is statistically significant with a $t$-statistic of 3.019. The results using two or more years of sales growth to form portfolios do not yield significant abnormal returns. For example, Panel B, which uses two-year sales growth to form portfolios, generates $0.1 \%$ abnormal returns and a $t$-statistic of 0.622 . In Panels $\mathrm{C}$ and $\mathrm{D}$ the abnormal returns become negative.

In addition to the industry-level portfolios, we form five portfolios (as described above) based on industry-level capacity utilization and firm-level sales growth. The results are reported in Table 5. Panels A-D of Table 5 reports result using one-year (Panel A) to four-year (Panel D) firm-level sales growth to form portfolios. Unlike the results using industry-level portfolios, sorting based on one-year sales growth does not yield significant abnormal returns. Using one-year sales growth to form portfolios generates $0.2 \%$ abnormal returns with a $t$-statistic of 0.988 . In contrast, using two-, three- or four-year sales growth to form portfolios generates significant abnormal returns. The $t$-statistic varies from 1.995 to 3.210. For example, using two-year sales growth generates $0.6 \%$ monthly abnormal returns and using three-year sales growth generates the highest abnormal returns of $0.8 \%$ monthly. These abnormal returns imply that investors can earn approximately 10\% annual abnormal returns trading on portfolios sorted on the interaction of sales growth and capacity utilization.

These results suggest that industries with high capacity utilization and high sales growth underperform (have low future returns) compared to firms operating in industries with low capacity utilization and low sales growth. Our findings are consistent with the hypothesis that investors are not fully able to incorporate the implications of capacity constraints for profit margins. Nevertheless, our tests are subject to the limitation of capacity utilization data, which is unavailable at the firm level. However, if the firm-level capacity utilization information is disclosed to investors, this may or may not improve the results depending on whether investors can now better identify the firm level capacity constraint. 


\subsection{Capital Expenditure and Capacity Constraint}

Our prediction about the relationship among capacity utilization, sales growth and profit margin relies on the argument that firms need to make additional capital expenditure to enlarge the capacity, therefore the profit margin falls following the increased fixed cost. In this section, we formally test this argument using the following regression:

$C A P X G_{i, t}=\alpha_{i, t}+\phi_{i} C A P X G_{i, t-1}+\beta_{i} \cdot \Delta$ Sales $_{t-1}+\gamma_{i} \cdot$ TcU $_{t-1}+\delta_{i} \cdot \Delta$ Sales $_{t-1} \cdot T C U_{t-1}+\varepsilon_{i, t}$

We estimate Equation (8) using a pooled regression. Our sample includes 44,958 firmyear observations. Our statistics are estimated with robust standard errors including year fixed effect and clustered by firm. Table 6 reports the regression results using different measures of sales growth as defined in the data section, similar to Table 3. As shown in Panel A Table 6, current period capital expenditure growth is positively related to last period's profit margin and negatively related to capital expenditure growth. $C A P X G_{t-1}$ is negatively related to last period's capacity utilization $\left(T C U_{t-1}\right)$, and statistically significant except in the first regression. $C A P X G_{t-1}$ is also negatively related to sales growth except in the first regression, but in general is not statistically significant except in the last regression using the four year compounded sales growth measure. These results suggest that firms do not immediately increase the capital expenditure when sales growth or capacity utilization alone is high. However, the interaction $S A L E G j_{t} * T C U_{t-1}$ is positively related to $C A P X G_{t-1}$, with coefficients varying from 0.108 to 0.277 and statistically significant with $t$-statistics varying from 2.05 to 3.16 except in the first regression. Therefore firms in industries with insufficient capacity are more likely to increase capital expenditure in the following period when sales growth remains high for the past successive periods. Firms do not appear to improve capital expenditure immediately when they are subject to a binding capacity constraint for just one single period. Instead they wait to see if the sales growth is going to remain high before making investments. Our capital expenditure measure might not capture all investments; however, it is still significantly related to the capacity constraint of the firm.

Another way of measuring the capital investment is the ratio of capital expenditure 
to depreciation, which is a cleaner measure of the new investment to enlarge the capacity beyond that to maintain current capacity. Therefore we also perform the test in Panel A Table 6 using $C A P X_{t} / D E P_{t}$ as the dependent variable. The result is reported in Panel B. Similar to Panel A, the results in Panel B show that $C A P X_{t} / D E P_{t}$ is positively related to the interaction $S A L E G J_{t} * T C U_{t-1}$, with coefficients varying from 0.444 to 0.808 , and $t$-statistics varying from 2.22 to 4.32 . As the measure of sales growth increases in horizon, the relation becomes more significant, which is consistent with our hypothesis that the firms are more likely to increase their capacity when the past sales growth remains high for a longer period.

To test whether the capital expenditure affects the impact of capacity constraint on the profit margin, we augment the regression in (6) including a categorical variable indicating firms with high capital expenditure growth in the previous period. For each year we sort firms into five quintile groups and define the variable $D$ which equals 1 if the firm's capital expenditure growth in year $t-1$ in the highest quintile group in year $t-1$ and otherwise zero. We then add the interaction $S A L E G j_{t} * T C U_{t-1} * D$ in regression (6) and conduct the regression using different sales growth measures. The results are reported in Panel A Table 7. Each column represents the result at different horizon's sales growth measure: $S A L E G 1_{t}$, $S A L E G 2_{t}, S A L E G 3_{t}$, and $S A L E G 4_{t}$. The coefficients of $S A L E G j_{t} * T C U_{t-1} * D$ is negative in all regressions varying from -0.001 to -0.004 , but only statistically significant in the first regression with $t$-statistic of -2.19. Similarly, we also perform the test in Panel A Table 7 using $C A P X_{t} / D E P_{t}$ instead of capital expenditure growth as the proxy to classify the dummy variable $D$, and results are reported in Panel B. The coefficients of $S A L E G j_{t} * T C U_{t-1} * D$ in Panel B are significantly negative for all sales growth measures with $t$-statistics from 5.93 to -8.3. Therefore firms with binding capacity constraints experience a larger decline in the future profit margin when they significantly increase their capital expenditure. This is consistent with our argument that the decline in the profit margin is driven by the increased fixed cost due to further investment in capacity. ${ }^{8}$

\footnotetext{
${ }^{8}$ Titman, Wei and Xie (2004) document that firms that firms with abnormal high capital expenditures tend to underperform. However, this works against finding our results as we predict a negative stock market
} 


\subsection{Controlling for the Accrual Anomaly}

Since our findings suggest a reversal of profit margins, it is useful to test whether our findings are subsumed by previously documented "reversal" anomalies, namely the accrual anomaly (Sloan, 1996). In particular, we augment our asset pricing model, Equation (7), with an accrual factor. Table 8 reports the abnormal returns, $\alpha_{p}$, estimates from the factor model including accrual factor. The accrual factor is the difference between the return on a portfolio with highest accruals and the return on a portfolio with lowest total accruals in the deciles. Total accruals are measured following Sloan (1996). Note that the accrual factor is inherently different than the momentum factor. While prior studies suggest that momentum returns compensate for liquidity risk (e.g., Pástor and Stambaugh, 2003; and Sadka, 2006), the accrual returns are generally considered anomalous, and therefore we do not include the accrual factor in our initial tests.

Table 8 reports results for portfolios formed on industry-level sales growth (Panel A) as well as firm-level sales growth (Panel B). For brevity, Table 8 reports only the abnormal returns and does not report the factor loadings. After controlling for the accrual factor, the portfolio return difference between the lowest and highest capacity utilization and sales growth quintile is $0.6 \%$ when using industry-level portfolios (using one-year sales growth), and statistically significant with a $t$-statistic of 2.421. Consistent with Table 4 , the abnormal returns decline when we use longer horizon sales growth to form portfolios.

Using firm-level sales growth (Panel B) yields similar results to Table 5. Using two-, three-, and four-year sales growth yields statistically significant abnormal returns. The $t$ statistic varies from 1.995 to 3.285 and the highest abnormal returns are obtained using three-year sales growth $(0.9 \%$ monthly). These returns are obtained after controlling for the accrual factor.

While our findings suggest that the returns obtained by trading based on capacity utilization and sales growth are not explained by risk, we caution the reader that one should

reaction when firms actually make new investment and profit margins decline. Moreover, in unreported results we do not find firms with high capital expenditure in our sample underperform. 
not exclude risk based explanations. The decline in the profit margin is due to additional investment. Significant changes to the firm caused by additional investment can significantly change its risk (factor loading). For example, Lamont (2000) suggests that investment plans rise when discount rates are lower. Also note that capacity utilization varies with the business conditions. However, our empirical model does not allow for time-varying risk loadings (see e.g., Bollerslev, Engle and Wooldridge, 1988; and Ang and Chen, 2007) and therefore may not provide an appropriate benchmark asset pricing model.

\subsection{Fama-MacBeth Regressions}

In addition to the factor model used in previous sections, we use the Fama and MacBeth (1973) approach. We regress returns on prior firm characteristics including, the book-tomarket ratio, size, accruals, sales growth, and an interaction term of sales growth and capacity utilization. Specifically, we employ the following regression:

$$
\begin{aligned}
R_{i, t}= & \alpha+\beta_{1} \cdot M V_{i, t-1}+\beta_{2} \cdot B M_{i, t-1}+\beta_{3} \cdot S A L E G j_{i, t-1} \\
& +\beta_{4} \cdot S A L E G j_{i, t-1} * T C U_{t-1}+\beta_{5} \cdot T A C C_{i, t-1}+\varepsilon_{i, t}
\end{aligned}
$$

where $B M_{i, t}$ denotes the book-to-market ratio and $T A C C_{i, t}$ denotes total accruals (following Sloan, 1996). The regressions are estimated for each cross section. Table 9 reports the average (time-series) coefficients and $t$-statistics.

The coefficient on the interaction term, $\beta_{4}$, is negative. The average coefficient varies from -0.042 to 0.706 and the $t$-statistic varies from -1.80 to -2.36 . The coefficient is statistically significant at the $5 \%$ level when using one-year and four-years sales growth. Apart from our interaction term, only accruals load negatively and statistically significant at the $5 \%$ level when we use one-year sales growth. In sum, our findings imply that the returns generated by employing a trading strategy based on the interaction of sales growth and capacity utilization is not subsumed by previously documented asset-pricing anomalies.

Note that while the book-to-market ratio commonly predicts returns, it does not in our sample. This result (or lack thereof) suggests that our sample is not representative of the 
entire sample of traded securities. This is also apparent in the time-series pricing models used in Tables 4, 5 and 8 where the intercepts are mainly positive. We do not believe this to be a major issue as we use the entire sample of industries that have data with regards to capacity utilization.

\section{Conclusion}

This paper studies the implications of capacity constraints on firms' profit margins and stock returns. We first document that firms' profit margins increase with sales and declines with sales for firms facing capacity constraints. Since firms are not required to disclose such information, we find that by using industry-level capacity utilization and both industry-level and firm-level sales, one can form a profitable trading strategy.

Our results may also indirectly provide guidance for regulators regarding the disclosure of firm-level capacity information. If firms were to disclose their capacity utilization then this information would be value relevant and lead to changes in the stock market value of the firm. However, depending on the nature of the imperfect market, disclosing capacity costs may also allow firms to coordinate with their rivals in an imperfect product market. The predicted stock market reaction can be either positive or negative. In reality, SEC grants firms an exemption from public disclosure if disclosure per se would harm the firms' overall value or erode future profits. 


\section{Appendix}

The firm maximizes its profits

$$
\max _{q} P \cdot q-C(q)=(A-q) \cdot q-c \cdot q-F \cdot \operatorname{integer}\left(\frac{q}{\bar{q}}+1\right)
$$

The first order conditions are undefined in cases where $[q / \bar{q}-$ integer $(q / \bar{q})] \rightarrow 1$. In all other cases the first order conditions are:

$$
A-2 q-c=0
$$

Rearranging Equation (11) to obtain the optimal output,

$$
q=\frac{A-c}{2}
$$

Substituting for $q$ in the demand function, Equation (1), to get prices

$$
P=\frac{A+c}{2}
$$

The accounting profit margin is the profit divided by sales

$$
P M=\frac{P \cdot q-C(q)}{P \cdot q}=1-\frac{C(q)}{P \cdot q}
$$

Substituting for $q, P$, and $C(q)$ in Equation (14) and rearrange, to get

$$
P M=1-\frac{c+\frac{2 F}{A-c} \text { integer }\left(\frac{A-c}{\overline{2 q}}+1\right)}{(A+c) / 2}
$$

These prices and quantities above are not optimal in cases where $[q / \bar{q}-$ integer $(q / \bar{q})] \rightarrow$ 1. The concern is that firms may choose to increase price and reduce quantities to avoid making an additional investment in capacity, $F$. Therefore, the firm may choose to produce at capacity while raising the price, rather than increasing production and incurring the additional costs, $F$. Once a firm chooses to increase capacity, the optimal prices and quantities 
are as stated in Equations (12) and (13). Thus, there is a range of $A \in\{\underline{A}(n), \bar{A}(n)\}$ where the firm's profits are higher by maintaining output at full capacity and increasing prices.

Let $n=\operatorname{integer}\left(\frac{A-c}{\overline{2 q}}\right)$. When $\underline{A}(n)=2 n \bar{q}+c$, the optimal output and price level are $n \bar{q}$ and $n \bar{q}+c$ respectively, which still satisfy the solution as in (12) and (13). However, if the demand slightly increases above this level to $\bar{A}(n)=2 n \bar{q}+c+\epsilon$, the firm may choose to raise price to maintain the output at $n \bar{q}$. The price will be set at $P=n \bar{q}+c+\epsilon$ when producing at the maximum capacity of $n \bar{q}$. Or the firm can decide to raise its capacity to $(n+1) \bar{q}$, then the price and output given $\bar{A}(n)$ will satisfy $(12)$ and $(13)$, i.e., $P=\frac{\bar{A}(n)+c}{2}$ and $q=\frac{\bar{A}(n)-c}{2}$.

Then the firm is indifferent between raising prices to avoid the increase in output and increasing capacity to the next level as long as the following equality holds:

$$
(n \bar{q}+\epsilon+c) n \bar{q}-n \bar{q} c-n F=\left(n \bar{q}+c+\frac{\epsilon}{2}\right)\left(n \bar{q}+\frac{\epsilon}{2}\right)-c\left(n \bar{q}+\frac{\epsilon}{2}\right)-(n+1) F
$$

The left hand side of the inequality is the profit of the firm if capacity is expanded and the right hand side represents the profits if the firm chooses not to increase output and capacity.

From (16), we have $\epsilon=\frac{\sqrt{F}}{2}$. For this comparison to be meaningful, we need also $\bar{A}(n)<$ $2(n+1) \bar{q}+c$, which gives us the following condition:

$$
\bar{q}^{2}>F
$$

As long as the above condition holds, there exists $\epsilon$ that equals $\frac{\sqrt{F}}{2}$ such that when the demand is between $\underline{A}(n)$ and $\bar{A}(n)$, as defined above, the firm decides not to increase capacity but to maintain the output at the maximum capacity level and increase the price.

Therefore the profit margin is given by:

$$
P M=\left\{\begin{array}{cc}
1-\frac{n \bar{q} c+n F}{(A-n \bar{q}) \cdot n \bar{q}} & \underline{A}(n) \leq A<\bar{A}(n) \\
1-\frac{c+\frac{2 F}{A-c}(n+1)}{(A+c) / 2} & \bar{A}(n) \leq A<\underline{A}(n+1)
\end{array}\right\}
$$

Next we need to show that the profit margin is increasing in output, but then experiences decline when the firm needs to increase capacity to adjust to the higher demand at $\bar{A}(n)$. 
We have shown that at $\bar{A}(n)$ the total profit remains the same whether or not the firm decides to increase its capacity. The profit margin depends on the sales revenue at these two output levels, i.e., $(n \bar{q}+c+\epsilon) n \bar{q}$ vs. $\left(n \bar{q}+c+\frac{\epsilon}{2}\right)\left(n \bar{q}+\frac{\epsilon}{2}\right)$. We can show that the following inequality holds:

$$
(n \bar{q}+c+\epsilon) n \bar{q}<\left(n \bar{q}+c+\frac{\epsilon}{2}\right)\left(n \bar{q}+\frac{\epsilon}{2}\right)
$$

As a result, when the firm raises the output for any demand greater than $\bar{A}(n)$, there will be an immediate decline in profit margin at $\bar{A}(n)$. It can be shown that before this point, the profit margin increases although the output remains at the capacity level; after this point, the profit margin increases as the output increases. 


\section{References}

Ang, Andrew and Joe Chen, CAPM over the long run: 1926-2001, Journal of Empirical Finance, $14,1,1-40$.

Badia, Marc, Nahum Melumad, and Doron Nissim, 2008, Operating profit variation analysis: Implications for future earnings and equity values, Working paper, Columbia University.

Banker, Rajiv and Lei Chen, 2006, Predicting earnings using a model based on cost variability and cost stickiness, The Accounting Review 81 (2), 285-307.

Banker, Rajiv, Srikant Datar, and Sunder Kekre, 1988, Relevant costs, congestion and stochasticity in production environments. Journal of Accounting $\&$ Economics 10 (3), 171-197.

Banker, Rajiv and John Hughes, 1994, Product costing and pricing, The Accounting Review 69 (3), 479-494.

Bollerslev, Tim, Robert F. Engle, and Jeffrey M. Wooldridge, 1988, A capital asset pricing model with time-varying covariances, The Journal of Political Economy, 96, 1, 116-131.

Carhart, Mark M., 1997, On persistence of mutual fund performance, Journal of Finance 52, 57-82.

Carlson, Murray D., Fisher, Adlai J., and Ron Giammarino, 2006, Corporate investment and asset price dynamics: implications for SEO event studies and long-run performance, Journal of Finance 59 (6), 2577-2603,

Corrado, Carol and Joe Mattey, 1997, Capacity Utilization, The Journal of Economic Perspectives 11 (1), 151-167.

Ertimur, Yonca, Joshua Livnat, and Minna Martikainen, 2003, Differential market reactions to revenue and expense surprises, Review of Accounting Studies 8, 185-211.

Fama, Eugene F., and Kenneth R. French, 1993, Common risk factors in the returns on stocks and bonds, Journal of Financial Economics, 33 (1), 3-56.

Fama, Eugene F., and James D. MacBeth, 1973, Risk, return, and equilibrium: Empirical tests, Journal of Political Economy, 81, 607-636.

Financial Accounting Standard Board, 2004, Statement of Financial Accounting Standards No. 151.

Finkel, Sidney R., and Donald L. Tuttle, 1971, Determinants of the aggregate profits margin, The Journal of Finance 26 (5), 1067-1075. 
Gunny, Katherine, 2009, The relation between earnings management using real activities manipulation and future performance: Evidence from meeting earnings benchmarks. Contemporary Accounting Research (forthcoming).

Jegadeesh, Narasimhan, and Sheridan Titman, 1993, Returns to buying winners and selling losers: implications for stock market efficiency. Journal of Finance 48, 65-91

Lamont, Owen A., 2000, Investment plans and stock returns, The Journal of Finance, 55 (6), 2719-2746.

Levitan, Richard and Martin Shubik, 1972, Price duopoly and capacity constraints, International Economic Review, 13 (1), 111-122.

Moskowitz, Tobias J., and Mark Grinblatt, 1999, Do industries explain momentum? The Journal of Finance 54 (4), Papers and Proceedings, 1249-1290.

Pástor, Ľuboš, and Robert F. Stambaugh, 2003, Liquidity risk and expected stock returns, Journal of Political Economy, 111, 642-685.

Roychowdhury, Sugata, 2006, Earnings management through real activity manipulation, Journal of Accounting and Economics 42 (3), 335-370.

Sadka, Ronnie, 2006, Momentum and post-earnings-announcement drift anomalies: The role of liquidity risk, Journal of Financial Economics 80, 309-349.

Sloan, Richard G, 1996, Do stock prices fully reflect information in cash flows and accruals about future earnings? The Accounting Review 71 (3), 289-315.

Titman, Sheridan, K.C. John Wei, and Feixue Xie, 2004, Capital investments and stock returns, Journal of Financial and Quantitative Analysis, 39, 677-700.

Vuolteenaho,Tuomo, 2002, What drives firm-level stock returns? Journal of Finance Vol 57, 233-264. 
Figure 1a Total Cost and Capacity Utilization: Numerical Example

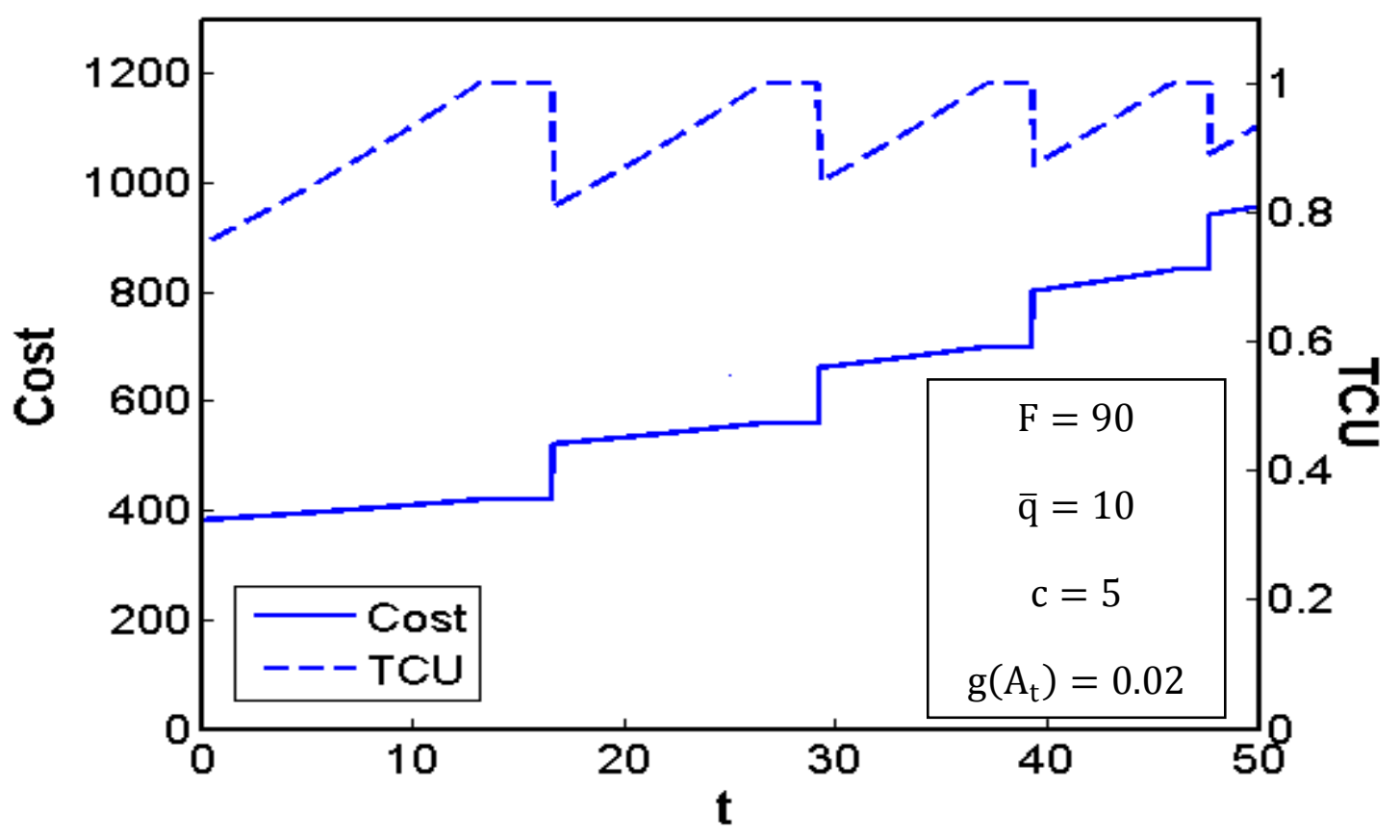

Figure 1b Profit Margin and Capacity Utilization: Numerical Example

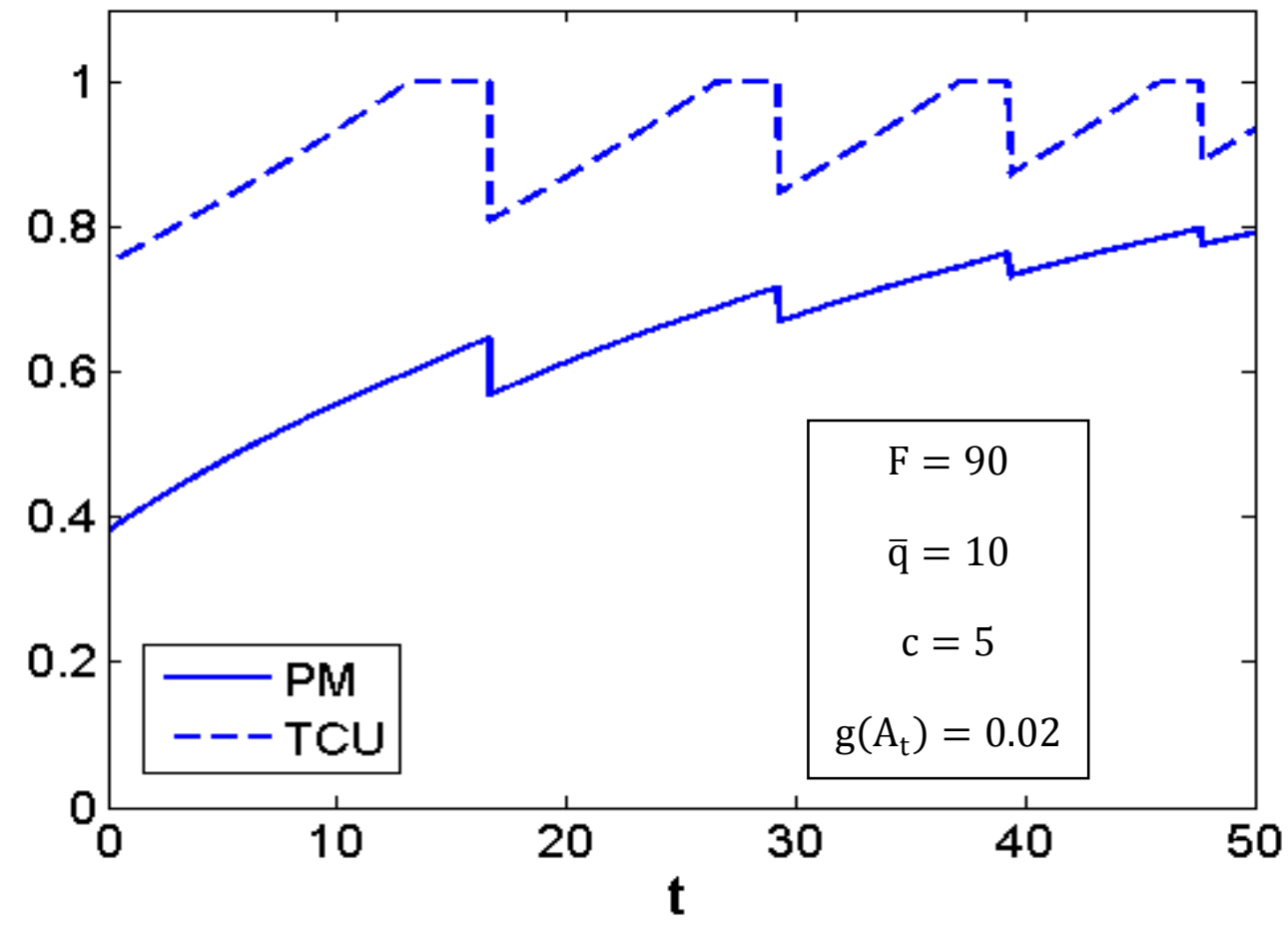




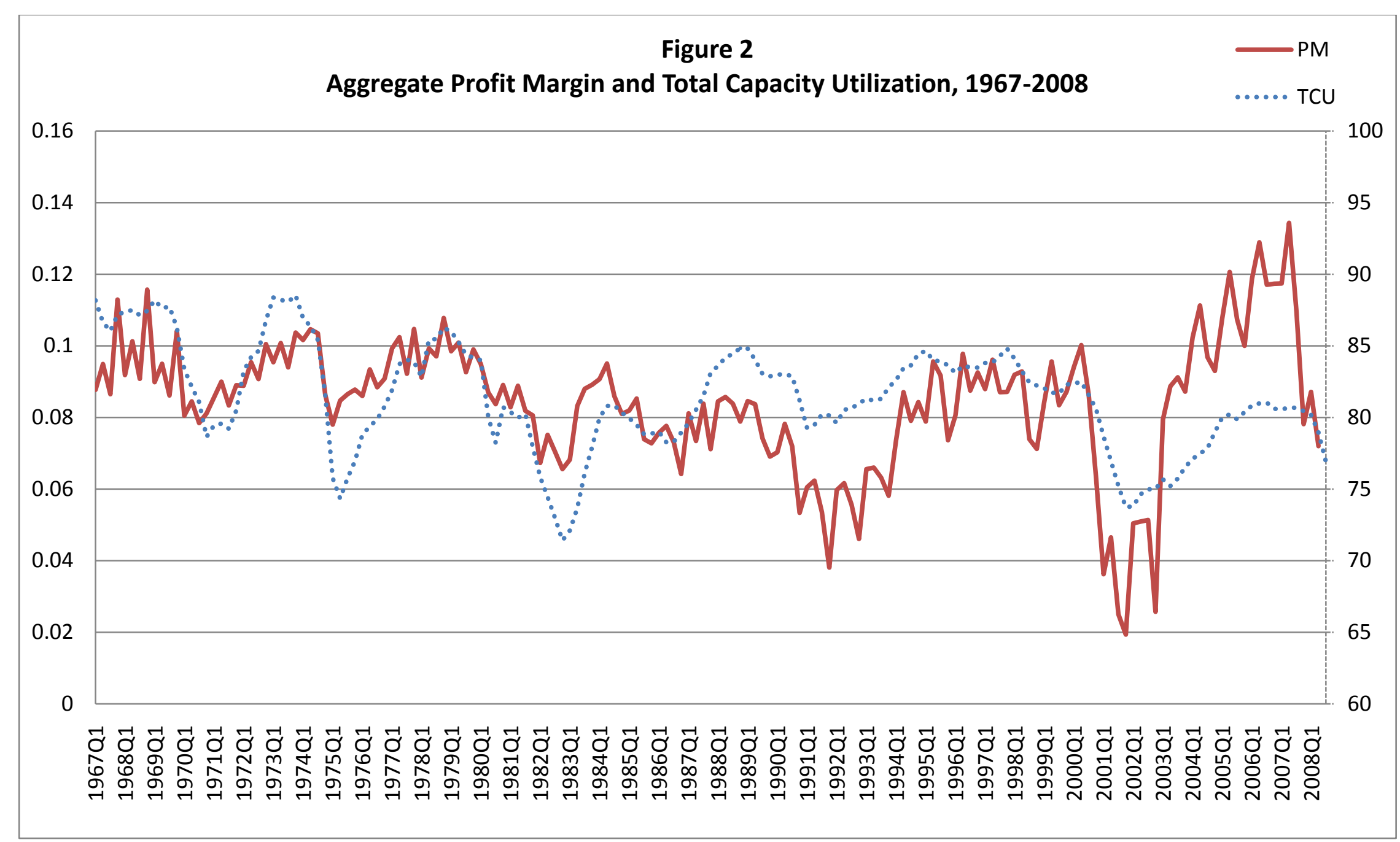

Figure 2 plots the time series of quarterly aggregate profit margin (PM) and total capacity utilization (TCU) from 1967 to 2008 . The aggregate profit margin is measured by the ratio of aggregate pre-tax income over aggregate sales for all the firms in the Compustat North America sample. The quarterly total capacity utilization is from Federal Reserve Statistical Release, available at http://www.federalreserve.gov/releases/G17/Current/default.htm 


\begin{tabular}{|c|c|}
\hline \multicolumn{2}{|c|}{$\begin{array}{c}\text { Table } 1 \\
\text { Industry Definition and NAICS codes }\end{array}$} \\
\hline Industry & NAICS \\
\hline Oil and gas extraction & 211 \\
\hline Mining (except oil and gas) & 212 \\
\hline Support activities for mining & 213 \\
\hline Electric power generation, transmission and distribution & 2211 \\
\hline Natural gas distribution & 2222 \\
\hline Food & 311 \\
\hline Beverage and tobacco product & 312 \\
\hline Textile mills & 313 \\
\hline Textile product mills & 314 \\
\hline Apparel & 315 \\
\hline Leather and allied product & 316 \\
\hline Wood product & 321 \\
\hline Paper & 322 \\
\hline Printing and related support activities & 323 \\
\hline Petroleum and coal products & 324 \\
\hline Chemical & 325 \\
\hline Plastics and rubber products & 326 \\
\hline Nonmetallic mineral product & 327 \\
\hline Primary metal & 331 \\
\hline Fabricated metal product & 332 \\
\hline Machinery & 333 \\
\hline Computer and electronic product & 334 \\
\hline Electrical equipment, appliance, and component & 335 \\
\hline Transportation equipment & 336 \\
\hline Furniture and related product & 337 \\
\hline Miscellaneous & 339 \\
\hline
\end{tabular}

The industry capacity utilization data and classification codes in this table are obtained from Federal Reserve Statistical Release at http://www.federalreserve.gov/releases/G17/g17caputl.txt 


\section{Table 2}

\section{Descriptive Statistics}

This table presents the descriptive statistics of key variables. The sample includes 44,958 firm-year observations from 1977 to 2008. $P M_{t}$ is the profit margin, defined as Pretax Income/Sales in year $t$ for each firm; $S A L E G i_{t}$ is defined as the compounded sales growth during the past $i$ years, i.e., $\boldsymbol{S A L E} \boldsymbol{G i}_{\boldsymbol{t}}=$ $\frac{\boldsymbol{S A L E G}_{t-1}}{\boldsymbol{S A L E G}_{t-2}} \times \frac{\boldsymbol{S A L E G}_{t-2}}{\boldsymbol{S A L E G}_{t-3}} \times \ldots \times \frac{\boldsymbol{S A L E G}_{t-i}}{\boldsymbol{S A L E G}_{t-i-1}} ; C A P G_{t}$ is the growth in capital expenditure in year $\mathrm{t}$, defined as $\mathrm{CAPX}_{\mathrm{t}} / \mathrm{CAPX}_{\mathrm{t}-1} ; T C U_{t}$ is the average total capacity utilization for the industry in year $\mathrm{t}$.

\begin{tabular}{lccccc}
\hline Panel A: Summary & \multicolumn{5}{c}{} \\
\cline { 2 - 6 } & Mean & Median & Std & Minimum & Maximum \\
\cline { 2 - 5 } PM $_{\boldsymbol{t}}$ & 0.058 & 0.068 & 0.118 & -3.245 & 0.273 \\
$\boldsymbol{S A L E G 1}_{\boldsymbol{t}}$ & 1.087 & 1.070 & 0.176 & 0.631 & 2.149 \\
$\boldsymbol{S A L E G}_{\boldsymbol{t}}$ & 1.207 & 1.156 & 0.318 & 0.420 & 4.219 \\
$\boldsymbol{S A L E G}_{\boldsymbol{t}}$ & 1.347 & 1.251 & 0.484 & 0.301 & 7.160 \\
$\boldsymbol{S A L E G}_{\boldsymbol{t}}$ & 1.522 & 1.364 & 0.711 & 0.232 & 13.801 \\
$\boldsymbol{C A P G}_{\boldsymbol{t}}$ & 1.183 & 1.068 & 0.603 & 0.214 & 4.417 \\
TCU $_{\boldsymbol{t}}$ & $80.19 \%$ & $80.74 \%$ & $7.02 \%$ & $37.41 \%$ & $97.84 \%$ \\
\hline
\end{tabular}

Panel B: Industry level correlation matrix (all p-values $<0.0001$ in the matrix below)

$\begin{array}{lllllll}\text { PM }_{t} & \text { SALEG1 }_{t} & \text { SALEG }_{t} & \text { SALEG3 }_{t} & \text { SALEG4 }_{t} & \text { CAPG }_{t} & \text { TCU }_{t-1}\end{array}$

$P M_{t}$

$\begin{array}{lllllll}\text { SALEG1 }_{\boldsymbol{t}} & 0.319 & & & & & \\ \text { SALEG2 }_{\boldsymbol{t}} & 0.241 & 0.804 & & & & \\ \text { SALEG3 }_{\boldsymbol{t}} & 0.223 & 0.618 & 0.854 & & & \\ \text { SALEG4 }_{\boldsymbol{t}} & 0.226 & 0.541 & 0.727 & 0.911 & & \\ \text { CAPG }_{\boldsymbol{t}} & 0.322 & 0.346 & 0.177 & 0.108 & 0.072 & \\ \text { TCU }_{t-1} & 0.171 & 0.314 & 0.342 & 0.308 & 0.275 & 0.088\end{array}$

Panel C: Firm level correlation matrix (all p-values $<0.0001$ in the matrix below)

$\begin{array}{lllllll}\text { PM }_{t} & \text { SALEG1 }_{t} & \text { SALEG2 }_{t} & \text { SALEG3 }_{t} & \text { SALEG4 }_{t} & \text { CAPG }_{t} & \text { TCU }_{t}\end{array}$

$\mathrm{PM}_{\mathrm{t}}$

SALEG1 $\quad 0.127$

SALEG2 $_{t} \quad 0.099 \quad 0.769$

SALEG3 $_{t} \quad 0.076 \quad 0.620 \quad 0.859$

$\begin{array}{lllll}\text { SALEG4 }_{t} & 0.046 & 0.527 & 0.735 & 0.899\end{array}$

$\begin{array}{llllll}\text { CAPG }_{\boldsymbol{t}} & 0.097 & 0.125 & 0.079 & 0.054 & 0.041\end{array}$

$\begin{array}{lllllll}\text { TCU }_{\boldsymbol{t}} & 0.105 & 0.098 & 0.103 & 0.080 & 0.054 & 0.006\end{array}$




\section{Table 3 \\ Profit Margin and Capacity Constraint}

This table reports the pooled regressions of profit margin on capacity constraint. The sample includes 44,958 firm-year observations from 1977 to 2008. $P M_{t}$ is the profit margin, defined as Pretax Income/Sales in year $\mathrm{t}$ for each firm; $S A L E G i_{t}$ is defined as the compounded sales growth during the past $i$ years, i.e., $\boldsymbol{S A L E G i _ { t }}=\frac{\boldsymbol{S A L E G _ { t - 1 }}}{\boldsymbol{S A L E G _ { t - 2 }}} \times \frac{\boldsymbol{S A L E G}_{t-2}}{\boldsymbol{S A L E G _ { t - 3 }}} \times \ldots \times \frac{\boldsymbol{S A L E G}_{t-i}}{\boldsymbol{S A L E G _ { t - i - 1 }}} ; C A P G_{t}$ is the growth in capital expenditure in year $\mathrm{t}$, defined as CAPX $\mathrm{CAPX}_{\mathrm{t}-1}$; $T C U_{t}$ is the average total capacity utilization for the industry in year t. $t$-statistic reported in parenthesis is the robust standard error with the year fixed effect and clustered standard error by firm.

\begin{tabular}{|c|c|c|c|c|}
\hline \multirow{3}{*}{ INTERCEPT } & \multicolumn{4}{|c|}{ Dependent Variable: $P M_{t}$} \\
\hline & -0.092 & -0.082 & -0.046 & -0.074 \\
\hline & $(-2.09)$ & $(-2.92)$ & $-(2.05)$ & $(-1.92)$ \\
\hline \multirow[t]{2}{*}{$P M_{t-1}$} & 0.654 & 0.657 & 0.657 & 0.657 \\
\hline & $(29.98)$ & $(29.97)$ & $(30.10)$ & $(30.30)$ \\
\hline \multirow[t]{2}{*}{$C A P X G_{t-1}$} & -0.007 & -0.006 & -0.006 & -0.006 \\
\hline & $(-6.86)$ & $(-6.05)$ & $(-6.08)$ & $(-6.02)$ \\
\hline \multirow[t]{2}{*}{$T C U_{t-1}$} & 0.144 & 0.144 & 0.098 & 0.087 \\
\hline & $(2.62)$ & $(4.09)$ & $(3.46)$ & (3.64) \\
\hline \multirow[t]{2}{*}{$S A L E G 1_{t}$} & 0.072 & & & \\
\hline & $(1.81)$ & & & \\
\hline \multirow{2}{*}{$S A L E G 1_{t}^{*} T C U_{t-1}$} & -0.087 & & & \\
\hline & $(-1.75)$ & & & \\
\hline \multirow[t]{2}{*}{$S A L E G 2_{t}$} & & 0.057 & & \\
\hline & & $(2.45)$ & & \\
\hline \multirow[t]{2}{*}{$S A L E G 2_{t}^{*} T C U_{t-1}$} & & -0.079 & & \\
\hline & & $(-2.76)$ & & \\
\hline \multirow[t]{2}{*}{$S A L E G 3_{t}$} & & & 0.023 & \\
\hline & & & $(1.41)$ & \\
\hline \multirow[t]{2}{*}{$S A L E G 3_{t}^{*} T C U_{t-1}$} & & & -0.036 & \\
\hline & & & $(-1.75)$ & \\
\hline \multirow[t]{2}{*}{$S A L E G 4_{t}$} & & & & 0.015 \\
\hline & & & & $(1.18)$ \\
\hline \multirow[t]{2}{*}{$S A L E G 4_{t}{ }^{* T C U_{t-1}}$} & & & & -0.024 \\
\hline & & & & $(-1.61)$ \\
\hline _ADJRSQ_ & 0.397 & 0.397 & 0.397 & 0.398 \\
\hline
\end{tabular}




\section{Table 4}

\section{Time Series Tests of Four-Factor Models for Capacity Constraint Portfolios: Industry Level}

This table reports estimates of the following four-factor model for monthly excess return on the quintile portfolios based on the capacity constraint:

$$
R_{p, t}-R_{f, t}=\alpha_{p}+\beta_{p, M}\left(R_{M, t}-R_{f, t}\right)+\beta_{p, H M L} H M L_{t}+\beta_{p, S M B} S M B_{t}+\beta_{p, U M D} U M D_{t}+\varepsilon_{p, t}
$$

where $\boldsymbol{R}_{\boldsymbol{M}, \boldsymbol{t}}-\boldsymbol{R}_{\boldsymbol{f}, \boldsymbol{t}}$ is the excess return on the market portfolio. $\boldsymbol{H} \boldsymbol{M} \boldsymbol{L}_{\boldsymbol{t}}, \boldsymbol{S} \boldsymbol{M} \boldsymbol{B}_{\boldsymbol{t}}$ and $\boldsymbol{U} \boldsymbol{M} \boldsymbol{D}_{\boldsymbol{t}}$ are the risk factors sorted based on size, book-to-market, and momentum, respectively. Each month stocks are sorted into five groups based on the industry average level of the interaction between last period's sales growth and total capacity utilization (SALEGi*TCU) at the end of the previous month. Panel A-D represents respectively the portfolio results based on different sales growth measure (SALEGi). We require the annual information at the end of the previous month to be within last 3 months. The portfolio return for each group is the equal weighted monthly return. The sample period is July 1977 through December 2008. $t$-statistic is reported in parenthesis.

\begin{tabular}{lccccc}
\hline \multicolumn{2}{l}{ Panel A: Portfolio based on SALEG1*TCU } & & & \\
\hline Portfolio & $A L P H A$ & $R_{M}-R_{F}$ & $S M B$ & $H M L$ & $U M D$ \\
\hline $\mathbf{1}$ & 0.011 & 0.961 & 0.593 & 0.501 & -0.047 \\
& $(6.63)$ & $(25.13)$ & $(11.55)$ & $(8.35)$ & $(-1.31)$ \\
\hline $\mathbf{2}$ & 0.006 & 0.963 & 0.714 & 0.270 & 0.026 \\
& $(3.56)$ & $(24.15)$ & $(13.32)$ & $(4.32)$ & $(0.70)$ \\
\hline $\mathbf{3}$ & 0.008 & 0.985 & 0.759 & 0.354 & -0.170 \\
& $(3.79)$ & $(19.76)$ & $(11.76)$ & $(4.63)$ & $(-3.75)$ \\
\hline $\mathbf{4}$ & 0.008 & 1.009 & 0.392 & 0.033 & -0.127 \\
& $(4.26)$ & $(23.64)$ & $(6.83)$ & $(0.49)$ & $(-3.14)$ \\
\hline $\mathbf{5}$ & 0.004 & 0.946 & 0.401 & 0.343 & 0.023 \\
& $(2.04)$ & $(20.94)$ & $(6.60)$ & $(4.84)$ & $(0.53)$ \\
\hline
\end{tabular}

Diff (1-5) $\quad 0.007$

(3.02)

\begin{tabular}{lccccc} 
Panel B: Portfolio based on SALEG2*TCU & & \\
\hline Portfolio & ALPHA & $R_{M}-R_{F}$ & SMB & HML & UMD \\
\hline $\mathbf{1}$ & 0.007 & 0.973 & 0.591 & 0.580 & -0.052 \\
& $(4.467)$ & $(27.089)$ & $(12.251)$ & $(10.300)$ & $(-1.523)$ \\
\hline $\mathbf{2}$ & 0.008 & 0.914 & 0.699 & 0.385 & 0.013 \\
& $(4.390)$ & $(22.109)$ & $(12.583)$ & $(5.938)$ & $(0.336)$ \\
\hline $\mathbf{3}$ & 0.008 & 1.028 & 0.559 & 0.137 & -0.128 \\
& $(4.582)$ & $(23.120)$ & $(9.709)$ & $(2.009)$ & $(-3.171)$ \\
\hline $\mathbf{4}$ & 0.010 & 1.030 & 0.502 & 0.051 & -0.185 \\
& $(5.001)$ & $(20.651)$ & $(7.483)$ & $(0.657)$ & $(-3.917)$ \\
\hline $\mathbf{5}$ & 0.005 & 0.937 & 0.461 & 0.271 & -0.004 \\
& $(2.880)$ & $(20.956)$ & $(7.668)$ & $(3.862)$ & $(-0.095)$ \\
\hline
\end{tabular}

Diff (1-5) $\quad 0.001$

$(0.622)$ 


\begin{tabular}{lccccc}
\hline Panel C: Portfolio based on SALEG3*TCU & & & \\
\hline Portfolio & $A L P H A$ & $R_{M^{-}} R_{F}$ & $S M B$ & $H M L$ & $U M D$ \\
\hline $\mathbf{1}$ & 0.006 & 0.957 & 0.543 & 0.539 & -0.025 \\
& $(3.810)$ & $(27.129)$ & $(11.467)$ & $(9.752)$ & $(-0.759)$ \\
\hline $\mathbf{2}$ & 0.006 & 0.941 & 0.526 & 0.462 & -0.021 \\
& $(3.745)$ & $(23.906)$ & $(9.944)$ & $(7.486)$ & $(-0.568)$ \\
\hline $\mathbf{3}$ & 0.007 & 0.971 & 0.772 & 0.355 & -0.114 \\
& $(3.935)$ & $(21.363)$ & $(13.127)$ & $(5.097)$ & $(-2.744)$ \\
\hline $\mathbf{4}$ & 0.011 & 1.007 & 0.648 & -0.064 & -0.133 \\
& $(5.854)$ & $(22.682)$ & $(10.861)$ & $-(0.916)$ & $(-3.162)$ \\
\hline $\mathbf{5}$ & 0.007 & 0.962 & 0.412 & 0.167 & -0.017 \\
& $(3.870)$ & $(20.635)$ & $(6.577)$ & $(2.285)$ & $(-0.396)$ \\
\hline Diff (1-5) & -0.002 & & & & \\
& $(-0.850)$ & & & & \\
\hline
\end{tabular}

\section{Panel D: Portfolio based on SALEG4*TCU}

\begin{tabular}{lccccc}
\hline Portfolio & ALPHA & $R_{M}-R_{F}$ & SMB & HML & UMD \\
\hline $\mathbf{1}$ & 0.006 & 0.942 & 0.448 & 0.550 & -0.002 \\
& $(4.106)$ & $(26.509)$ & $(9.389)$ & $(9.880)$ & $(-0.050)$ \\
\hline $\mathbf{2}$ & 0.006 & 0.942 & 0.635 & 0.399 & -0.076 \\
& $(3.708)$ & $(22.814)$ & $(11.447)$ & $(6.170)$ & $(-1.946)$ \\
\hline $\mathbf{3}$ & 0.006 & 0.985 & 0.602 & 0.515 & -0.046 \\
& $(3.319)$ & $(23.052)$ & $(10.873)$ & $(7.842)$ & $(-1.184)$ \\
\hline $\mathbf{4}$ & 0.008 & 1.077 & 0.538 & 0.222 & 0.004 \\
& $(4.283)$ & $(25.160)$ & $(9.355)$ & $(3.316)$ & $(0.087)$ \\
\hline $\mathbf{5}$ & 0.011 & 0.897 & 0.635 & -0.278 & -0.190 \\
& $(5.256)$ & $(18.407)$ & $(9.698)$ & $-(3.640)$ & $(-4.135)$ \\
\hline Diff (1-5) & -0.005 & & & & \\
& $(-1.859)$ & & & & \\
\hline
\end{tabular}




\section{Table 5}

\section{Time Series Tests of Four-Factor Models for Capacity Constraint Portfolios: Firm Level}

This table reports estimates of the following four-factor model for monthly excess return on the quintile portfolios based on the capacity constraint:

$$
R_{p, t}-R_{f, t}=\alpha_{p}+\beta_{p, M}\left(R_{M, t}-R_{f, t}\right)+\beta_{p, H M L} H M L_{t}+\beta_{p, S M B} S M B_{t}+\beta_{p, U M D} U M D_{t}+\varepsilon_{p, t}
$$

where $\boldsymbol{R}_{\boldsymbol{M}, \boldsymbol{t}}-\boldsymbol{R}_{\boldsymbol{f}, \boldsymbol{t}}$ is the excess return on the market portfolio. $\boldsymbol{H} \boldsymbol{M} \boldsymbol{L}_{\boldsymbol{t}}, \boldsymbol{S} \boldsymbol{M} \boldsymbol{B}_{\boldsymbol{t}}$ and $\boldsymbol{U} \boldsymbol{M} \boldsymbol{D}_{\boldsymbol{t}}$ are the risk factors sorted based on size, book-to-market, and momentum, respectively. Each month stocks are sorted into five groups based on the firm level of the interaction between last period's sales growth and total capacity utilization (SALEGi*TCU) at the end of the previous month. Panel A-D represents respectively the portfolio results based on different sales growth measure (SALEGi). We require the annual information at the end of the previous month to be within last 3 months. The portfolio return for each group is the equal weighted monthly return. The sample period is July 1977 through December 2008. $t$ statistic is reported in parenthesis.

\begin{tabular}{lccccc}
\hline Panel A: Portfolio based on SALEG1 & TCU & & & \\
\hline Portfolio & $A L P H A$ & $R_{M^{-}} R_{f}$ & $S M B$ & $H M L$ & $U M D$ \\
\hline $\mathbf{1}$ & 0.008 & 0.911 & 0.794 & 0.312 & -0.092 \\
& $(4.714)$ & $(21.223)$ & $(13.763)$ & $(4.640)$ & $(-2.256)$ \\
\hline $\mathbf{2}$ & 0.011 & 0.958 & 0.596 & 0.306 & -0.094 \\
& $(7.523)$ & $(27.839)$ & $(12.890)$ & $(5.676)$ & $(-2.887)$ \\
\hline $\mathbf{3}$ & 0.008 & 0.983 & 0.589 & 0.328 & -0.050 \\
& $(5.445)$ & $(27.303)$ & $(12.188)$ & $(5.816)$ & $(-1.464)$ \\
\hline $\mathbf{4}$ & 0.006 & 0.972 & 0.445 & 0.272 & -0.037 \\
& $(4.135)$ & $(30.357)$ & $(10.335)$ & $(5.413)$ & $(-1.227)$ \\
\hline $\mathbf{5}$ & 0.006 & 0.943 & 0.517 & -0.029 & -0.067 \\
& $(3.048)$ & $(19.418)$ & $(7.932)$ & $-(0.383)$ & $(-1.466)$ \\
\hline
\end{tabular}

Diff (1-5) 0.002

(0.988)

\begin{tabular}{lccccc}
\multicolumn{7}{l}{ Panel B: Portfolio based on SALEG2*TCU } \\
\hline Portfolio & ALPHA & $R_{M^{-}} R_{f}$ & SMB & HML & UMD \\
\hline $\mathbf{1}$ & 0.011 & 0.894 & 0.758 & 0.364 & -0.078 \\
& $(6.062)$ & $(20.559)$ & $(12.975)$ & $(5.337)$ & $(-1.897)$ \\
\hline $\mathbf{2}$ & 0.008 & 0.961 & 0.593 & 0.301 & -0.100 \\
& $(5.203)$ & $(25.998)$ & $(11.953)$ & $(5.191)$ & $(-2.860)$ \\
\hline $\mathbf{3}$ & 0.007 & 0.980 & 0.541 & 0.338 & -0.027 \\
& $(4.950)$ & $(28.182)$ & $(11.591)$ & $(6.196)$ & $(-0.809)$ \\
\hline $\mathbf{4}$ & 0.006 & 0.945 & 0.477 & 0.178 & -0.052 \\
& $(4.242)$ & $(26.187)$ & $(9.835)$ & $(3.155)$ & $(-1.512)$ \\
\hline $\mathbf{5}$ & 0.005 & 1.079 & 0.594 & 0.110 & -0.101 \\
& $(3.138)$ & $(26.866)$ & $(11.013)$ & $(1.749)$ & $(-2.672)$ \\
\hline
\end{tabular}

Diff (1-5) $\quad 0.006$

(2.341) 


\begin{tabular}{lccccc}
\hline Panel C: Portfolio based on SALEG3*TCU & & & \\
\hline Portfolio & $A L P H A$ & $R_{M}-R_{f}$ & $S M B$ & $H M L$ & $U M D$ \\
\hline $\mathbf{1}$ & 0.012 & 0.901 & 0.675 & 0.271 & -0.078 \\
& $(6.674)$ & $(20.492)$ & $(11.436)$ & $(3.938)$ & $(-1.887)$ \\
\hline $\mathbf{2}$ & 0.007 & 0.948 & 0.567 & 0.336 & -0.054 \\
& $(4.984)$ & $(26.944)$ & $(12.002)$ & $(6.097)$ & $(-1.617)$ \\
\hline $\mathbf{3}$ & 0.006 & 1.004 & 0.551 & 0.403 & -0.065 \\
& $(4.117)$ & $(29.455)$ & $(12.025)$ & $(7.547)$ & $(-2.020)$ \\
\hline $\mathbf{4}$ & 0.008 & 0.923 & 0.552 & 0.163 & -0.049 \\
& $(5.429)$ & $(25.565)$ & $(11.389)$ & $(2.877)$ & $(-1.450)$ \\
\hline $\mathbf{5}$ & 0.004 & 1.079 & 0.612 & 0.109 & -0.114 \\
& $(2.638)$ & $(26.718)$ & $(11.277)$ & $(1.720)$ & $(-2.992)$ \\
\hline Diff (1-5) & 0.008 & & & & \\
& $(3.210)$ & & & & \\
\hline
\end{tabular}

\section{Panel D: Portfolio based on SALEG4*TCU}

\begin{tabular}{lccccc}
\hline Portfolio & ALPHA & $R_{M}-R_{f}$ & SMB & HML & UMD \\
\hline $\mathbf{1}$ & 0.012 & 1.006 & 0.640 & 0.319 & -0.111 \\
& $(5.909)$ & $(21.357)$ & $(10.116)$ & $(4.321)$ & $(-2.502)$ \\
\hline $\mathbf{2}$ & 0.009 & 0.820 & 0.558 & 0.310 & -0.046 \\
& $(5.596)$ & $(20.907)$ & $(10.594)$ & $(5.046)$ & $(-1.240)$ \\
\hline $\mathbf{3}$ & 0.005 & 0.935 & 0.529 & 0.337 & 0.003 \\
& $(3.422)$ & $(28.751)$ & $(12.103)$ & $(6.606)$ & $(0.103)$ \\
\hline $\mathbf{4}$ & 0.006 & 1.007 & 0.522 & 0.269 & -0.044 \\
& $(4.229)$ & $(29.493)$ & $(11.382)$ & $(5.033)$ & $(-1.355)$ \\
\hline $\mathbf{5}$ & 0.007 & 1.081 & 0.709 & 0.040 & -0.159 \\
& $(4.090)$ & $(27.234)$ & $(13.301)$ & $(0.641)$ & $(-4.237)$ \\
\hline Diff (1-5) & 0.005 & & & & \\
& $(1.995)$ & & & & \\
\hline
\end{tabular}




\section{Table 6 \\ Capital Expenditure and Capacity Constraint}

This table reports the pooled regressions of capital investment on capacity constraint. The sample includes 44,958 firm-year observations from 1977 to 2008. Panel A presents the results using the capital expenditure growth as a measure of investment. $C A P X G_{t}$ is the growth in capital expenditure in year $t$, defined as $\mathrm{CAPX}_{\mathrm{t}} / \mathrm{CAPX}_{\mathrm{t}-1}$. Panel $\mathrm{B}$ presents the results using the capital expenditure to depreciation ratio as a measure of investment. $C A P X_{t} / D E P_{t}$ is the ratio of capital expenditure in year t to the depreciation in year t. $P M_{t}$ is the profit margin, defined as Pretax Income/Sales in year t for each firm; $S A L E G 1_{t}$ is the last year's sales growth, defined as $\mathrm{SALES}_{\mathrm{t}-1} / \mathrm{SALES}_{\mathrm{t}-2}$; $S A L E G 2_{t}$ is the compounded last two years' sales growth, defined as $\mathrm{SALES}_{\mathrm{t}-1} / \mathrm{SALES}_{\mathrm{t}-2} * \mathrm{SALES}_{\mathrm{t}-2} / \mathrm{SALES}_{\mathrm{t}-3} ; S A L E G 3_{t}$ is the compounded sales growth in last three years, defined as $\mathrm{SALES}_{\mathrm{t}-1} / \mathrm{SALES}_{\mathrm{t}-2} * \mathrm{SALES}_{\mathrm{t}-2} / \mathrm{SALES}_{\mathrm{t}-3} * \mathrm{SALES}_{\mathrm{t}-3} / \mathrm{SALES}_{\mathrm{t}-4}$; SALEG4 ${ }_{t}$ is the compounded sales growth in last four years, defined as SALES $\mathrm{t}_{\mathrm{t}-1} / \mathrm{SALES}_{\mathrm{t}-2} * \mathrm{SALES}_{\mathrm{t}-2} / \mathrm{SALES}_{\mathrm{t}-3} * \mathrm{SALES}_{\mathrm{t}-}$ ${ }_{3} / \mathrm{SALES}_{\mathrm{t}-4} * \mathrm{SALES}_{\mathrm{t}-4} / \mathrm{SALES}_{\mathrm{t}-5} ; T C U_{t}$ is the average total capacity utilization for the industry in year $\mathrm{t}$. $t$ statistic reported in parenthesis is the robust standard error with the year fixed effect and clustered standard error by firm.

\begin{tabular}{|c|c|c|c|c|}
\hline \multicolumn{5}{|c|}{ Panel A: Dependent Variable: $C A P X G_{t}$} \\
\hline \multirow[t]{2}{*}{ INTERCEPT } & 1.114 & 1.552 & 1.637 & 1.639 \\
\hline & $(5.16)$ & $(11.63)$ & $(16.75)$ & $(21.15)$ \\
\hline \multirow[t]{2}{*}{$P M_{t-1}$} & 0.308 & 0.359 & 0.398 & 0.417 \\
\hline & $(9.44)$ & $(10.56)$ & $(11.33)$ & $(11.76)$ \\
\hline \multirow[t]{2}{*}{$C A P X G_{t-1}$} & -0.160 & -0.147 & -0.137 & -0.133 \\
\hline & $(-30.87)$ & $(-28.54)$ & $(-26.52)$ & $(-25.78)$ \\
\hline \multirow[t]{2}{*}{$T C U_{t-1}$} & -0.372 & -0.551 & -0.528 & -0.483 \\
\hline & $(-1.38)$ & $(-3.32)$ & $(-4.35)$ & $(-5.02)$ \\
\hline \multirow[t]{2}{*}{$S A L E G_{1}$} & 0.389 & & & \\
\hline & $(1.96)$ & & & \\
\hline \multirow[t]{2}{*}{$S A L E G_{1} * T C U_{t-1}$} & 0.131 & & & \\
\hline & $(0.54)$ & & & \\
\hline \multirow[t]{2}{*}{$S A L E G_{2}$} & & -0.025 & & \\
\hline & & $(-0.32)$ & & \\
\hline \multirow[t]{2}{*}{$S A L E G_{2} * T C U_{t-1}$} & & 0.277 & & \\
\hline & & $(2.05)$ & & \\
\hline \multirow[t]{2}{*}{$S A L E G_{3}$} & & & -0.111 & \\
\hline & & & $(-1.60)$ & \\
\hline \multirow[t]{2}{*}{$S A L E G_{3} * T C U_{t-1}$} & & & 0.239 & \\
\hline & & & (2.77) & \\
\hline \multirow[t]{2}{*}{$S{ }^{\prime} E G_{4}$} & & & & -0.108 \\
\hline & & & & $(-2.26)$ \\
\hline \multirow[t]{2}{*}{$S A L E G_{4} * T C U_{t-1}$} & & & & 0.187 \\
\hline & & & & (3.16) \\
\hline $\operatorname{Adj}-R^{2}$ & 0.061 & 0.051 & 0.045 & 0.022 \\
\hline
\end{tabular}




\begin{tabular}{|c|c|c|c|c|}
\hline \multicolumn{5}{|c|}{ Panel B: Dependent Variable: $C A P X_{t} / D E P_{t}$} \\
\hline \multirow[t]{2}{*}{ INTERCEPT } & 0.586 & 0.735 & 0.737 & 0.702 \\
\hline & $(1.84)$ & (3.77) & $(4.87)$ & $(5.57)$ \\
\hline \multirow[t]{2}{*}{$P M_{t-1}$} & 0.807 & 0.839 & 0.865 & 0.882 \\
\hline & $(12.50)$ & $(12.82)$ & (12.99) & (13.13) \\
\hline \multirow[t]{2}{*}{$C A P X_{t-1} / D E P_{t-1}$} & 0.587 & 0.586 & 0.587 & 0.588 \\
\hline & (41.29) & $(40.75)$ & (40.78) & $(40.84)$ \\
\hline \multirow[t]{2}{*}{$T C U_{t-1}$} & -0.190 & -0.125 & -0.047 & 0.044 \\
\hline & $(-0.48)$ & $(-0.51)$ & $(-0.25)$ & $(0.28)$ \\
\hline \multirow[t]{2}{*}{$S A L E G_{1}$} & -0.324 & & & \\
\hline & $(-1.10)$ & & & \\
\hline \multirow[t]{2}{*}{$S A L E G_{1} * T C U_{t-1}$} & 0.808 & & & \\
\hline & $(2.22)$ & & & \\
\hline \multirow[t]{2}{*}{$S A L E G_{2}$} & & -0.414 & & \\
\hline & & $(-2.49)$ & & \\
\hline \multirow[t]{2}{*}{$S A L E G_{2} * T C U_{t-1}$} & & 0.690 & & \\
\hline & & $(3.35)$ & & \\
\hline \multirow[t]{2}{*}{$S A L E G_{3}$} & & & -0.386 & \\
\hline & & & $(-3.38)$ & \\
\hline \multirow[t]{2}{*}{$S A L E G_{3} * T C U_{t-1}$} & & & 0.565 & \\
\hline & & & (3.97) & \\
\hline \multirow[t]{2}{*}{$\mathrm{SALEG}_{4}$} & & & & -0.324 \\
\hline & & & & $(-3.95)$ \\
\hline \multirow[t]{2}{*}{$S A L E G_{4} * T C U_{t-1}$} & & & & 0.444 \\
\hline & & & & $(4.32)$ \\
\hline Adj-R ${ }^{2}$ & 0.463 & 0.462 & 0.461 & 0.461 \\
\hline
\end{tabular}


Table 7

Profit Margin and Capacity Constraint: the Impact of Capital Expenditure

This table reports the pooled regressions of profit margin on capacity constraint with the proxy for the high investment in the last period. The sample includes 44,958 firm-year observations from 1977 to 2008. . Panel A presents the results using the capital expenditure growth as a measure of investment. $C A P X G_{t}$ is the growth in capital expenditure in year $\mathrm{t}$, defined as $\mathrm{CAPX}_{\mathrm{t}} / \mathrm{CAPX}_{\mathrm{t}-1}$. Panel $\mathrm{B}$ presents the results using the capital expenditure to depreciation ratio as a measure of investment. $C A P X_{t} / D E P_{t}$ is the ratio of capital expenditure in year t to the depreciation in year t. $D$ is a dummy variable which equals 1 if the firm's capital investment measure $\left(C A P X G_{t-1}\right.$ or $\left.C A P X_{t-1} / D E P_{t-1}\right)$ in year $\mathrm{t}-1$ in the highest quintile group in year t-1. $P M_{t}$ is the profit margin, defined as Pretax Income/Sales in year $t$ for each firm; $S A L E G 1_{t}$ is the last year's sales growth, defined as $\mathrm{SALES}_{\mathrm{t}-1} / \mathrm{SALES}_{\mathrm{t}-2} ; S A L E G 2_{t}$ is the compounded last two years' sales growth, defined as SALES $_{\mathrm{t}-1}$ /SALES $_{\mathrm{t}-2} * \mathrm{SALES}_{\mathrm{t}-2} / \mathrm{SALES}_{\mathrm{t}-3} ; S A L E G 3_{t}$ is the compounded sales growth in last three years, defined as $\mathrm{SALES}_{\mathrm{t}-1} / \mathrm{SALES}_{\mathrm{t}-2} * \mathrm{SALES}_{\mathrm{t}-2} / \mathrm{SALES}_{\mathrm{t}-}$ ${ }_{3}{ }^{*} \mathrm{SALES}_{\mathrm{t}-3} / \mathrm{SALES}_{\mathrm{t}-4} ; \mathrm{SALEG}_{t}$ is the compounded sales growth in last four years, defined as $\mathrm{SALES}_{\mathrm{t}-}$ ${ }_{1} / \mathrm{SALES}_{\mathrm{t}-2} * \mathrm{SALES}_{\mathrm{t}-2} / \mathrm{SALES}_{\mathrm{t}-3} * \mathrm{SALES}_{\mathrm{t}-3} / \mathrm{SALES}_{\mathrm{t}-4} * \mathrm{SALES}_{\mathrm{t}-4} / \mathrm{SALES}_{\mathrm{t}-5} ; \quad T C U_{t}$ is the average total capacity utilization for the industry in year t. Each column in the table represents the regression results when the sales growth is measured differently. $t$-statistic reported in parenthesis is the robust standard error with the year fixed effect and clustered standard error by firm.

\begin{tabular}{|c|c|c|c|c|}
\hline \multicolumn{5}{|c|}{ Panel A: capital investment measured by $C A P X G_{t-1}$} \\
\hline & $S A L E G_{1}$ & $S A L E G_{2}$ & $S A L E G_{3}$ & $S A L E G_{4}$ \\
\hline \multirow[t]{2}{*}{ INTERCEPT } & -0.091 & -0.082 & -0.047 & -0.037 \\
\hline & $(-2.08)$ & $-(2.92)$ & $(-2.06)$ & $(-1.93)$ \\
\hline \multirow[t]{2}{*}{$P M_{t-1}$} & 0.653 & 0.656 & 0.657 & 0.657 \\
\hline & (29.54) & (29.79) & (29.96) & (30.19) \\
\hline \multirow[t]{2}{*}{$C A P X G_{t-1}$} & -0.005 & -0.004 & -0.005 & -0.005 \\
\hline & $(-3.22)$ & $(-3.04)$ & $(-3.27)$ & $(-3.51)$ \\
\hline \multirow[t]{2}{*}{$T C U_{t-1}$} & 0.140 & 0.141 & 0.097 & 0.084 \\
\hline & $(2.54)$ & (4.03) & $(3.40)$ & (3.61) \\
\hline \multirow[t]{2}{*}{ SALEG } & 0.070 & 0.056 & 0.023 & 0.014 \\
\hline & $(1.76)$ & (2.39) & (1.37) & (1.15) \\
\hline \multirow[t]{2}{*}{$S A L E G * T C U_{t-1}$} & -0.083 & -0.077 & -0.035 & -0.023 \\
\hline & $(-1.66)$ & $(-2.67)$ & $(-1.67)$ & $(-1.56)$ \\
\hline \multirow[t]{2}{*}{$S A L E G * T C U_{t-1} * D$} & -0.004 & -0.003 & -0.002 & -0.001 \\
\hline & $(-2.19)$ & $(-1.69)$ & $(-1.41)$ & $(-1.17)$ \\
\hline Adj-R ${ }^{2}$ & 0.397 & 0.397 & 0.398 & 0.398 \\
\hline
\end{tabular}


Panel B: capital investment measured by $C A P X_{t-1} / D E P_{t-1}$

\begin{tabular}{|c|c|c|c|c|}
\hline & $S A L E G_{1}$ & $S A L E G_{2}$ & $S A L E G_{3}$ & $\mathrm{SALEG}_{4}$ \\
\hline \multirow[t]{2}{*}{ INTERCEPT } & -0.079 & -0.072 & $\begin{array}{l}-0.038 \\
\end{array}$ & -0.029 \\
\hline & $(-1.80)$ & $(-2.54)$ & $(-1.67)$ & $(-1.51)$ \\
\hline \multirow[t]{2}{*}{$P M_{t-1}$} & 0.650 & 0.653 & 0.653 & 0.653 \\
\hline & $(28.36)$ & (28.69) & $(28.85)$ & $(29.00)$ \\
\hline \multirow[t]{2}{*}{$C A P X_{t-1} / D E P_{t-1}$} & 0.001 & 0.001 & 0.001 & 0.002 \\
\hline & $(1.60)$ & (1.79) & (1.94) & $(2.01)$ \\
\hline \multirow[t]{2}{*}{$T C U_{t-1}$} & 0.131 & 0.133 & 0.090 & 0.079 \\
\hline & (2.38) & (3.80) & (3.19) & (3.61) \\
\hline \multirow[t]{2}{*}{ SALEG } & 0.063 & 0.051 & 0.021 & 0.013 \\
\hline & $(1.60)$ & (2.19) & $(1.22)$ & (1.04) \\
\hline \multirow[t]{2}{*}{$S A L E G^{*} T C U_{t-1}$} & -0.075 & -0.071 & -0.031 & -0.021 \\
\hline & $(-1.51)$ & $(-2.45)$ & $(-1.49)$ & $(-1.39)$ \\
\hline \multirow[t]{2}{*}{$S A L E G * T C U_{t-1} * D$} & -0.011 & -0.008 & -0.007 & -0.006 \\
\hline & $(-8.30)$ & $(-6.70)$ & $(-6.36)$ & $(-5.93)$ \\
\hline Adj-R ${ }^{2}$ & 0.397 & 0.397 & 0.398 & 0.398 \\
\hline
\end{tabular}




\section{Table 8 \\ Time Series Test for Capacity Constraint Portfolios with Accrual Factor}

This table reports the estimates of $A L P H A s$ from the factor model including the accrual factor for monthly excess return on the quintile portfolios based on the capacity constraint. ALPHA is the excess return based on the following four factor model:

$$
R_{p, t}-R_{f, t}=\alpha_{p}+\beta_{p, M}\left(R_{M, t}-R_{f, t}\right)+\beta_{p, H M L} H M L_{t}+\beta_{p, S M B} S M B_{t}+\beta_{p, U M D} U M D_{t}+\varepsilon_{p, t}
$$

where $\boldsymbol{R}_{\boldsymbol{M}, \boldsymbol{t}}-\boldsymbol{R}_{\boldsymbol{f}, \boldsymbol{t}}$ is the excess return on the market portfolio. $\boldsymbol{H} \boldsymbol{M} \boldsymbol{L}_{\boldsymbol{t}}, \boldsymbol{S} \boldsymbol{M} \boldsymbol{B}_{\boldsymbol{t}}$ and $\boldsymbol{U} \boldsymbol{M} \boldsymbol{D}_{\boldsymbol{t}}$ are the risk factors sorted based on size, book-to-market, and momentum, respectively. The accrual factor is the difference between the return on a portfolio with highest accruals and the return on a portfolio with lowest total accruals in the deciles. Total accruals are measured following Sloan (1996). Each month stocks are sorted into five groups based on the industry or firm level of the interaction between last period's sales growth and total capacity utilization (SALEGi*TCU) at the end of the previous month. We require the annual information at the end of the previous month to be within last 3 months. The portfolio return for each group is the equal weighted monthly return. The sample period is July 1977 through December 2008. $t$-statistic is reported in parenthesis.

\begin{tabular}{|c|c|c|c|c|}
\hline \multicolumn{5}{|c|}{ Panel A: Industry level } \\
\hline Portfolio & SALEG1 & SALEG2 & SALEG3 & SALEG4 \\
\hline \multirow[t]{2}{*}{1} & 0.011 & 0.007 & 0.006 & 0.007 \\
\hline & $(6.535)$ & $(4.655)$ & $(4.181)$ & $(4.634)$ \\
\hline \multirow[t]{2}{*}{2} & 0.006 & 0.007 & 0.007 & 0.007 \\
\hline & $(3.546)$ & $(4.085)$ & (4.068) & $(3.932)$ \\
\hline \multirow[t]{2}{*}{3} & 0.006 & 0.009 & 0.008 & 0.006 \\
\hline & $(2.872)$ & $(5.085)$ & $(4.072)$ & $(3.372)$ \\
\hline \multirow[t]{2}{*}{4} & 0.009 & 0.011 & 0.009 & 0.009 \\
\hline & (4.831) & (4.829) & $(4.803)$ & (4.988) \\
\hline \multirow[t]{2}{*}{5} & 0.005 & 0.007 & 0.009 & 0.008 \\
\hline & $(2.738)$ & $(3.487)$ & (4.409) & (3.938) \\
\hline \multirow[t]{2}{*}{ Diff (1-5) } & 0.006 & 0.001 & -0.003 & -0.001 \\
\hline & $(2.421)$ & $(0.342)$ & $(-1.122)$ & $(-0.362)$ \\
\hline \multicolumn{5}{|c|}{ Panel B: Firm level } \\
\hline Portfolio & SALEG1 & SALEG2 & SALEG3 & SALEG4 \\
\hline \multirow[t]{2}{*}{1} & 0.007 & 0.011 & 0.012 & 0.012 \\
\hline & $(3.643)$ & $(5.502)$ & $(6.286)$ & $(6.011)$ \\
\hline \multirow[t]{2}{*}{2} & 0.012 & 0.009 & 0.008 & 0.010 \\
\hline & $(8.025)$ & (5.579) & (5.027) & (5.511) \\
\hline \multirow[t]{2}{*}{3} & 0.009 & 0.007 & 0.006 & 0.005 \\
\hline & (5.790) & (4.647) & (4.274) & (3.159) \\
\hline \multirow[t]{2}{*}{4} & 0.006 & 0.007 & 0.009 & 0.007 \\
\hline & (4.359) & (4.395) & (5.809) & (4.376) \\
\hline \multirow[t]{2}{*}{5} & 0.006 & 0.005 & 0.004 & 0.006 \\
\hline & $(2.922)$ & (2.959) & $(2.076)$ & (3.676) \\
\hline \multirow[t]{2}{*}{ Diff (1-5) } & 0.000 & 0.005 & 0.009 & 0.006 \\
\hline & $(0.189)$ & (1.995) & (3.285) & (2.321) \\
\hline
\end{tabular}




\section{Testing Capacity Constraint Factor with Fama-Macbeth Standard Errors}

This table reports estimates of the following model using Fama-Macbeth approach:

$$
\begin{aligned}
& R_{E T} T_{i, t}=\alpha+\beta_{1} S I Z E_{i, t-1}+\beta_{2} B M_{i, t-1}+\beta_{3} S A L E G_{i, t-1} \\
& \quad+\beta_{4} S A L E G_{i, t-1} * T C U_{t-1}+\beta_{5} * T A C C_{i, t-1}+\varepsilon_{i, t}
\end{aligned}
$$

For each month, the cross sectional regression of the above model is performed and then the t-statistic of time series mean of each coefficient is reported in the table below. SIZE $E_{i t}$ is the log value of market value of firm $i$ at the end of last fiscal year. $B M_{i t}$ is the book-to-market ratio of firm $i$ at the end of last fiscal year. SALEG is the sales growth based on different compounding measures. SALEG *TCU is the interaction between the last period's sales growth and total capacity utilization. TACC $_{i t}$ is the total accruals measured following Sloan (1996) for firm $i$ at the end of last fiscal year. We require the annual information at the end of the previous month to be within last 3 months. The sample period is July 1977 through December 2008. The mean and $t$-statistic of each coefficient are reported.

\begin{tabular}{lcccc}
\hline & SALEG1 & SALEG2 & SALEG3 & SALEG4 \\
\hline INTERCEPT & 0.011 & 0.013 & 0.025 & 0.052 \\
& $(0.55)$ & $(0.79)$ & $(1.61)$ & $(1.43)$ \\
\hline \multirow{2}{*}{ IZE } & -0.001 & -0.001 & -0.002 & -0.003 \\
& $(-0.93)$ & $(-0.76)$ & $(-1.76)$ & $(-1.46)$ \\
\hline SALEG & 0.010 & 0.007 & 0.011 & 0.006 \\
& $(1.68)$ & $(1.09)$ & $(1.59)$ & $(0.76)$ \\
\hline SALEG*TCU & 0.061 & 0.038 & 0.030 & 0.022 \\
& $(1.70)$ & $(1.54)$ & $(1.44)$ & $(1.07)$ \\
\hline TACC & -0.706 & -0.051 & -0.042 & -0.044 \\
& $(-2.36)$ & $(-1.84)$ & $(-1.80)$ & $(-2.14)$ \\
\hline
\end{tabular}

